\title{
Editorial
}

\section{Advanced Catalysis and Nanostructure Design for Solar Energy Conversion}

\author{
Shaohua Shen, ${ }^{1}$ Ke Sun, ${ }^{2}$ Haimin Zhang, ${ }^{3}$ and Yongqi Liang ${ }^{4}$ \\ ${ }^{1}$ International Research Center for Renewable Energy, State Key Laboratory of Multiphase Flow in Power Engineering, \\ Xian Jiaotong University, Xian, Shaanxi 710049, China \\ ${ }^{2}$ Joint Center for Artificial Photosynthesis, California Institute of Technology, Pasadena, CA 91125, USA \\ ${ }^{3}$ Centre for Clean Environment and Energy, Environmental Futures Centre, Griffith University, Gold Coast, QLD 4215, Australia \\ ${ }^{4}$ Department of Chemistry, Umeå University, 90187 Umeå, Sweden
}

Correspondence should be addressed to Shaohua Shen; shshen_xjtu@mail.xjtu.edu.cn

Received 29 June 2014; Accepted 29 June 2014; Published 7 July 2014

Copyright (C) 2014 Shaohua Shen et al. This is an open access article distributed under the Creative Commons Attribution License, which permits unrestricted use, distribution, and reproduction in any medium, provided the original work is properly cited.

\begin{abstract}
Solar energy conversion has been intensively studied in past decades and has been shown to be greatly effective for solving the serious environmental pollution and energy shortage problems. Photoelectrocatalysis and photovoltaics have been considered as the two main approaches for solar energy conversion and utilization, which are generally involved with nanostructured materials and/or catalytic processes, greatly affecting the efficiencies for solar energy conversion. Then, it is necessary to understand the relationship between the physical and chemical properties of nanomaterials and their performances for solar energy conversion. It is also important to explore the fundamentals in catalytic processes for solar energy conversion and make breakthrough in design and synthesis of nanomaterials or nanostructures, characterization of material properties, and performance of novel devices and systems. The aim of this special issue is to present some recent progress in the field of advanced catalysis and nanostructure design for solar energy conversion. A brief summary of all accepted papers is provided below.

The article entitled "Effect of heating method on hydrogen production by biomass gasification in supercritical water" investigated the gasification of glucose as a test sample of biomass in supercritical water with different heating methods driven by renewable solar energy. The relations between temperature raising speed of reactant fluid, variation of volume fraction, combustion enthalpy, and chemical energy of $\mathrm{H}_{2}$ of the product gases and reactant solution concentration
\end{abstract}

were presented, respectively. The results showed that the energy quality of product gases with preheating process was higher than that with no preheating unit for hydrogen production. Hydrogen production quantity and gasification rate of glucose decreased obviously with the increase of concentration of material in no preheating system.

The article entitled "Hydrogen production by supercritical water gasification of biomass with homogeneous and heterogeneous catalyst" selected $\mathrm{Ca}(\mathrm{OH})_{2}, \mathrm{Na}_{2} \mathrm{CO}_{3}, \mathrm{~K}_{2} \mathrm{CO}_{3}, \mathrm{NaOH}$, $\mathrm{KOH}, \mathrm{LiOH}$, and $\mathrm{ZnCl}_{2}$ as typical homogeneous catalysts and three kinds of Raney-Ni, dolomite, and olivine as typical heterogeneous catalysts. The catalyst effects were investigated in the process of biomass gasification in supercritical water with the temperature of $400^{\circ} \mathrm{C}$, pressure of $\mathrm{MPa}$, and residence time of $20 \mathrm{~min}$. The experimental results showed that Raney$\mathrm{Ni}$ had the best hydrogen selectivity and hydrogen yield and Raney-Ni and $\mathrm{NaOH}$ had a synergistic effect in the biomass gasification in supercritical water.

The article entitled "Revisiting the zinc-blende/wurtzite heterocrystalline structure in CdS" revisited the band offset at CdS zinc-blende (ZB)/wurtzite (WZ) heterocrystalline interface using the first principles calculations with the local density approximation (LDA), generalized gradient approximation (GGA), and Heyd-Scuseria-Ernzerhof (HSE06) hybrid functional. It was revealed that, unlike most IV, III-V, and II-VI semiconductors, the band alignment at CdS ZB/WZ heterocrystalline interface was of type-I with straddling 
lineup of band edges, which was irrespective of the exchangecorrelation energy functional, the thickness of $\mathrm{ZB}$ and $\mathrm{WZ}$ segments, and the $\mathrm{ZB} / \mathrm{WZ}$ interface location. The partial charge densities of VBM and CBM states were separated around two adjacent interfaces in one unit cell of heterocrystalline superlattice. This type of carrier localization was mainly attributed to the spontaneous polarization occurring in the WZ segment rather than the band offset at the interface.

In the article entitled "Preparation and characterization of novel $\mathrm{Fe}_{2} \mathrm{O}_{3}$-flaky coated carbon fiber by electrospinning and hydrothermal methods," a novel hierarchical nanostructure of $\mathrm{Fe}_{2} \mathrm{O}_{3}$-flaky coated carbon fibers was produced by the electrospinning process followed by a hydrothermal technique. First, electrospinning of a colloidal solution that consisted of ferric nitrate and polyacrylonitrile (PAN) was performed to produce PAN nanofibers. Then electrospun nanofiber was stabilized and calcinated in nitrogen at $800^{\circ} \mathrm{C}$ for $2 \mathrm{~h}$ to produce carbon nanofibers (CNFs) which were exploited to produce $\mathrm{Fe}_{2} \mathrm{O}_{3}$-flaky structure using hydrothermal technique. $\mathrm{Fe}_{2} \mathrm{O}_{3}$-flaky coated carbon fibers displayed high photocatalytic activity toward degradation of methyl orange (MO) under visible light irradiation.

The article entitled "Diffusion-controlled growth of oxygen bubble evolved from nanorod-array $\mathrm{TiO}_{2}$ photoelectrode" investigated the structure's effects on solid-liquid interface interaction and reaction product transportation on the gas-evolving photoelectrode for photoelectrochemical water splitting. By experimental studies of wettability on the photoelectrode nanorod-array surface and oxygen bubble growth from anode, the interaction affecting the gas-solid-liquid contact behaviors and product transportation mechanism was analyzed, which was controlled by diffusion due to the concentration gradient of dissolved gases in the aqueous electrolyte and the microconvection caused by the bubble interface movement. In the end, based on the bubble growth characteristics of $R_{B}(t) \sim t^{0.5}$ in the experiment, a model describing the product transport mechanism was presented.

In the article entitled "Effects of absorber emissivity on thermal performance of a solar cavity receiver," the thermal performances of the receiver with different absorber emissivity were numerically simulated. The results showed that the thermal efficiency increases and the total heat loss decreases with increasing emissivity of absorber tubes. However, the thermal efficiency increases by only $1.6 \%$ when the emissivity of tubes varies from 0.2 to 0.8 . Therefore, the change of absorber emissivity had slight effect on the thermal performance of the receiver. The reason for variation tendency of performance curves was also carefully analyzed. It was found that the temperature reduction of the cavity walls causes the decrease of the radiative heat loss and the convective heat loss.

In the article entitled "Fabrication of $\mathrm{TiO}_{2}$ nanofilm photoelectrodes on $\mathrm{Ti}$ foil by $\mathrm{Ti}$ ion implantation and subsequent annealing," the $\mathrm{TiO}_{2}$ photoelectrodes fabricated on the substrate of Ti foils by $\mathrm{Ti}$ ions implantation and subsequent annealing at different temperatures were applied for water splitting. The size of $\mathrm{TiO}_{2}$ nanoparticles increased with annealing temperatures, and the GIXRD patterns and Raman spectra demonstrated that the phase of $\mathrm{TiO}_{2}$ turned to rutile at high temperature. The photoelectrochemical (PEC) and X-ray photoelectron spectroscopy (XPS) spectra of the valence band demonstrated that the samples annealed at 400 and $500^{\circ} \mathrm{C}$ showed the n-type property. The sample annealed at $600^{\circ} \mathrm{C}$ showed the weak p-type $\mathrm{TiO}_{2}$ property. For the sample annealed at $700^{\circ} \mathrm{C}$, the negative photocurrent was main, which mainly performed the p-type property of $\mathrm{TiO}_{2}$. The IPCE values indicated that the absorption edges were red shifted with the increase of annealing temperatures.

In the article entitled "Equivalent circuit analysis of photovoltaic-thermoelectric hybrid device with different TE module structure," the experimental data of dye-sensitized solar cells (DSSCs) and thermoelectric generators (TEG) were simulated by equivalent circuit method, and some parameters of DSSCs were obtained. Then, the equivalent circuit model with the obtained parameters was used to optimize the structure design of photovoltaic- (PV-) thermoelectric (TE) hybrid devices. The output power first increased to a maximum and then decreased by increasing the TE prism size, and a smaller spacing between $\mathrm{p}$-type prism and n-type prism of a TE $\mathrm{p}$-n junction caused a higher output power of TEG and hybrid device. When the spacing between TE prisms was $15 \mu \mathrm{m}$ and the optimal base side length of TE prism was $40 \mu \mathrm{m}$, the maximum theoretical efficiency reached $24.6 \%$ according to the equivalent circuit analysis. This work would give some enlightenment for the development of high-performance PV-TE hybrid devices.

In the article entitled "Improved composite gel electrolyte by layered vermiculite for quasi-solid-state dye-sensitized solar cells," a composite quasisolid electrolyte was prepared by adding a layered vermiculite (VMT) into the iodide/triiodide electrolyte including 4-tert-butylpyridine, which obviously improved the photovoltaic properties of quasisolid dyesensitized solar cells (DSSCs). When adding $6 \mathrm{wt} \% \mathrm{VMT}$, the maximum photovoltaic conversion efficiency of $3.89 \%$ was obtained, which reached more than two times greater than that without VMT. This enhancement effect was primarily explained by studying the Nyquist spectra, dark currents, and photovoltaic conversion efficiency.

In the article entitled "Photocatalytic reduction of $\mathrm{CO}_{2}$ to methane on $\mathrm{Pt} / \mathrm{TiO}_{2}$ nanosheet porous film," anatase $\mathrm{TiO}_{2}$ nanosheet porous films were prepared by calcination of the orthorhombic titanic acid films at $400^{\circ} \mathrm{C}$. They showed an excellent photocatalytic activity for $\mathrm{CO}_{2}$ photoreduction to methane, which should be related to their special porous structure and large Brunauer-Emmett-Teller (BET) surface area. In order to further improve the photocatalytic activity, Pt nanoparticles were loaded uniformly with the average size of 3-4 nm on $\mathrm{TiO}_{2}$ porous films by the photoreduction method. It was found that the loading of Pt expanded the light absorption ability of the porous film and improved the transformation efficiency of $\mathrm{CO}_{2}$ to methane. The conversion yield of $\mathrm{CO}_{2}$ to methane on $\mathrm{Pt} / \mathrm{TiO}_{2}$ film reached $20.51 \mathrm{ppm} / \mathrm{h} \cdot \mathrm{cm}^{2}$. The $\mathrm{Pt} / \mathrm{TiO}_{2}$ nanosheet porous film was characterized by means of X-ray diffraction (XRD), scanning electron microscopy (SEM), transmission electron microscope (TEM), and ultraviolet-visible light diffuse reflectance spectra (UV-vis DRS). Moreover, the transient 
photocurrent-time curves showed that the $\mathrm{Pt} / \mathrm{TiO}_{2}$ nanosheet porous film exhibited higher photocurrent, indicating that the higher separation efficiency of the photogenerated charge carriers was achieved.

In the article entitled "Preparation and photocatalytic activity of $\mathrm{Ag}$ modified Ti-doped- $\mathrm{Bi}_{2} \mathrm{O}_{3}$ photocatalyst," Tidoped- $\mathrm{Bi}_{2} \mathrm{O}_{3}$ (TDB) and $\mathrm{Ag}$ ion modified Ti-doped- $\mathrm{Bi}_{2} \mathrm{O}_{3}$ (Ag@TDB) photocatalysts were prepared by framework replacement synthesis method with different $\mathrm{Ag}$ loadings $\left(0.05,0.3,0.75\right.$, and $\left.1.0 \mathrm{~mol} / \mathrm{L} \mathrm{AgNO}_{3}\right)$. The structural properties of the prepared catalysts were studied by scanning electron microscope (SEM), X-ray diffraction (XRD), BET surface area, and UV/Vis diffuse reflectance spectra (DRS). The XRD spectra of the Ti-doped- $\mathrm{Bi}_{2} \mathrm{O}_{3}$ calcined at $650^{\circ} \mathrm{C}$ showed the diffraction peaks of a mixture of $\mathrm{Bi}_{12} \mathrm{TiO}_{20}$ and $\mathrm{Bi}_{4} \mathrm{Ti}_{3} \mathrm{O}_{12}$, with bits of mixed crystallite consisting of $\mathrm{TiO}_{2}$ and $\mathrm{B}_{2} \mathrm{O}_{3}$. A high blue shift in the range $650-550 \mathrm{~nm}$ was detected in the DRS band. This blue shift increased with the decreasing Ag content. The photocatalytic activities of the catalysts were evaluated for the degradation of crystal violet (CV) under UV light irradiation. The results indicated that the degradation rate of $\mathrm{CV}$ by using $1.0 \mathrm{~mol} / \mathrm{L} \mathrm{AgNO}_{3}$ doped bismuth titanate composite photocatalyst (1.0 Ag@TDB) was 1.9 times higher than that by using the bare Ti-doped- $\mathrm{Bi}_{2} \mathrm{O}_{3}$ photocatalyst. The higher activity of Ag@TDB was due to the enhancement of electron-hole pair separation by the electron trapping of silver particles.

The article entitled "Visible-light-driven photocatalytic degradation of aniline over $\mathrm{NaBiO}_{3}$ " investigated the photocatalytic activity for degradation of aniline over $\mathrm{NaBiO}_{3}$. It was found that $\mathrm{pH}$ and $\mathrm{NaBiO}_{3}$ dosage had played important role in the photocatalytic degradation. To scrutinize the mechanistic details of the aniline photodegradation, several critical analytical methods including spectroscopy and GC/MS were utilized to detect the temporal course of the reaction. Intermediates and several small molecular products were separated and identified, such as $\mathrm{C}_{2} \mathrm{H}_{5} \mathrm{O}_{3} \mathrm{~N}$, $\mathrm{C}_{10} \mathrm{H}_{13} \mathrm{O}_{2} \mathrm{~N}$, and $\mathrm{C}_{12} \mathrm{H}_{10} \mathrm{~N}_{2}$. Then two possible photodegradation pathways of aniline over $\mathrm{NaBiO}_{3}$ were proposed: ring opening and mineralization.

\section{Acknowledgments}

We would like to express our thanks to all authors who made this special issue possible. We hope that the readers of this issue will find interesting information on advanced catalysis and nanostructure design for solar energy conversion.

Shaohua Shen

Ke Sun

Haimin Zhang

Yongqi Liang 

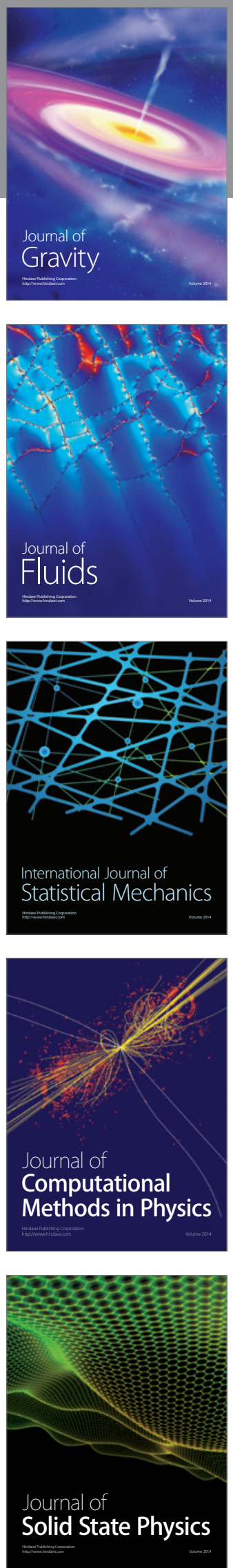

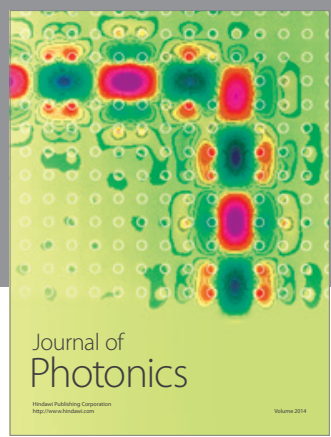

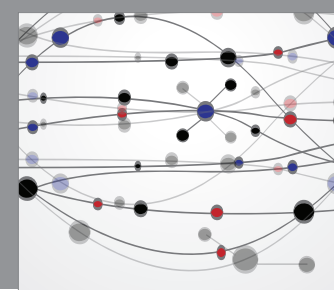

The Scientific World Journal

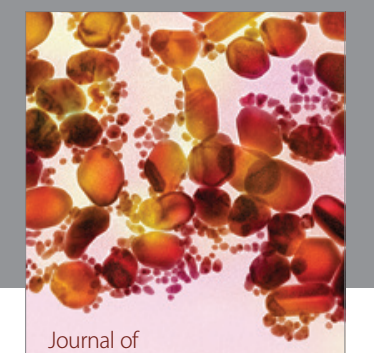

Soft Matter
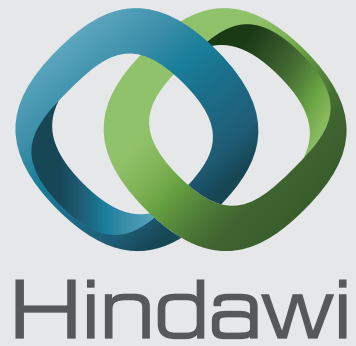

Submit your manuscripts at

http://www.hindawi.com
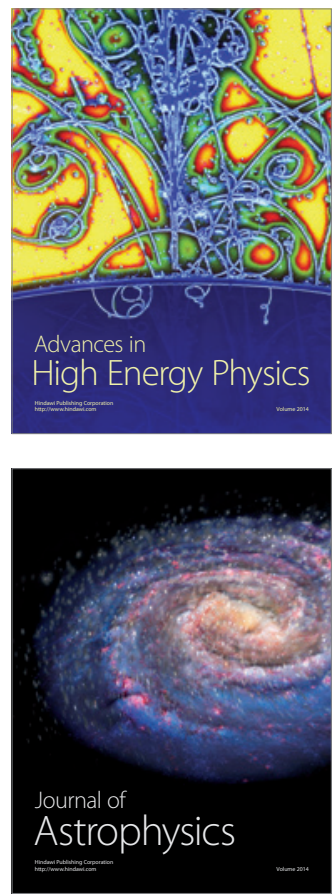
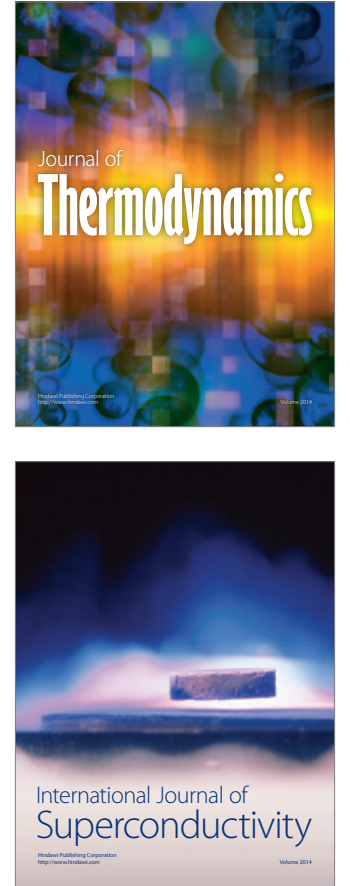
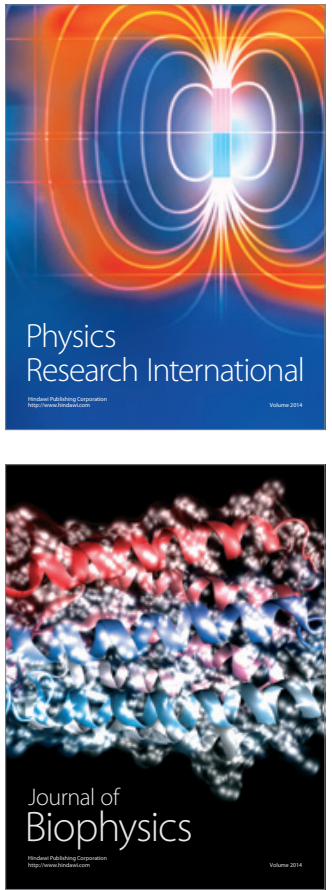
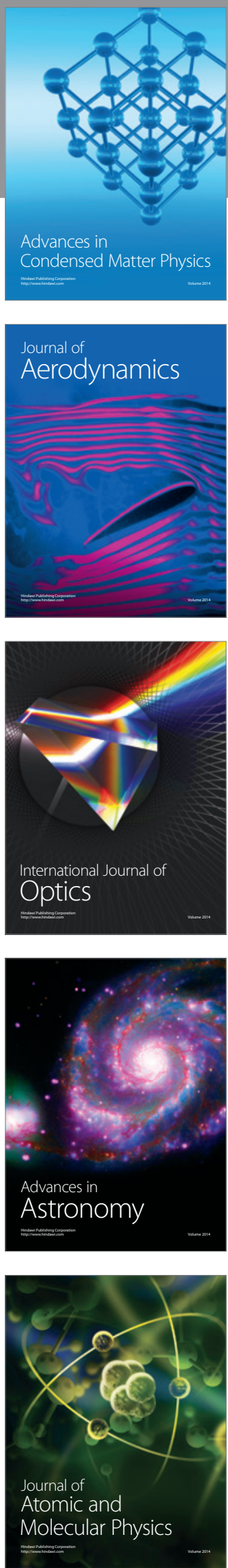